\title{
A Lagrangian analysis of the Indian-Atlantic interocean exchange in a regional model
}

\author{
A. M. Doglioli,1 M. Veneziani,2,3 B. Blanke,1 S. Speich,1 A. Griffa,2,4
}

\author{
1 Laboratoire de Physique des Océans, UMR 6523 CNRS/IFREMER/UBO, Brest, France \\ 2 RSMAS/MPO, University of Miami, Miami, USA \\ 3 now at UC Santa Cruz, USA \\ 4 ISMAR/CNR, La Spezia, Italia
}

\begin{abstract}
We present a new numerical Lagrangian technique based on the coupling of transport computation with spin analysis of trajectories. This method was applied to results from a highresolution numerical model of the oceanic region around South Africa. We estimated an Indian-Atlantic leakage of about $14 \mathrm{~Sv}$. In the western Cape Basin, approximately 30\% of this transport is due to trapping eddies with a ratio between cyclones and anticyclones transport of 1.3. These findings are briefly discussed with respect to recent observations of the highly nonlinear regime found in this area of the Cape Basin
\end{abstract}




\section{Introduction}

Interocean exchanges of water around South Africa play a key role in the global ocean overturning circulation of the ocean [Gordon, 1986]. They are thought to consist of three major parts: Agulhas-rings, -filaments and the direct transport of intermediate water [de Ruijter et al., 1999, and references therein]. Several cyclones have also been observed in the Cape Basin [Boebel et al., 2003a]. Results of the KAPEX observational program have shown the extreme complexity and variability of all components of the exchange [e.g., Lutjeharms et al., 2003; Schmid et al., 2003]. Thus, the connection between oceans could be inhibited by this high nonlinear regime [de Ruijter et al., 1999].

Numerical simulations of interocean fluxes can be of great help in complementing observational studies and in leading to a better understanding of the involved dynamics. As reviewed by de Ruijter et al. [1999], model-based diagnostics have been used in several attempts to estimate the rates of mass, heat and salt exchange. More recently, Matano and Beier [2003] analyzed numerical simulations performed with the Parallel Ocean Circulation Model (POCM) with an average grid spacing of $\frac{1}{4}^{\circ}$ and 20 vertical levels. Their volume balance indicates that the Cape Basin gains approximately $20 \mathrm{~Sv}$ of surface and intermediate waters from the Indian Ocean and exports a similar amount to the South Atlantic subtropical gyre. In a study of a regional eddy-permitting model based on the Modular Ocean Model, Reason et al. [2003] pointed out the high variability of exchanges characterized by scales within the seasonal and regional ones.

Numerical Lagrangian particles constitute a powerful tool to investigate the origin of water masses. Speich et al. [2001] used a Lagrangian particle-following technique to re- 
construct a climatological picture of the upper branch of the Great Ocean Conveyor Belt by using the ORCA numerical model of the global ocean. Their results emphasized the role of the Indo-Atlantic connection hypothesized by Gordon et al. [1992]. Donners and Drijfhout [2004] employed a similar technique to investigate the interocean exchange of thermocline and intermediate waters in the South Atlantic Ocean by using the OCCAM global ocean general circulation model. They showed that more than $90 \%$ of the flow toward the North Atlantic originate from the Indian Ocean via leakage from the Agulhas Current system.

In order to more thoroughly evaluate the Indian-Atlantic leakage, we develop a Lagrangian particles-based diagnostic of a high resolution $\left(\frac{1}{10}^{\circ}\right)$ regional model of the Agulhas system. Furthermore, we attempt to evaluate the contribution of trapping eddies to the interocean exchange by coupling a Lagrangian particle-following technique with a "spin"-based analysis of trajectories. The goal is to separate the trajectories into two subsets associated with two different dynamical regimes: i) the subset of particles embedded in coherent vortices, the so-called "loopers", and ii) the subset of those remaining in a more quiescent "background" flow region, the so-called "nonloopers". A simple qualitative criterion to identify loopers was initially introduced by Richardson [1993], who defined a looper as a trajectory that undergoes at least two consecutive loops in the same direction. The method applied here is more quantitative and suited to the treatment of extensive data sets. It is based on the computation of the spin parameter and it has previously been applied to in-situ data and numerical trajectories [Veneziani et al., 2004; Veneziani et al., 2005b]. The spin, $\Omega$, is related to the angular velocity of the Lagrangian eddy velocity 
vector and corresponds to the vorticity field for trajectories embedded inside vortex cores [Veneziani et al., 2005a]; according to these authors this parameter well characterizes the effects of rotating structures. We, therefore, estimate the percentage of transport directly due to trapping eddies from a spin analysis of the trajectories of particles leaking from the Agulhas current system to the Atlantic Ocean.

\section{Method}

\subsection{Regional Circulation Model}

Our circulation model is based on the IRD (Institut de Recherche pour le Développement) version of the Regional Ocean Modeling System (ROMS) [Shchepetkin and McWilliams, 2005]. Its domain extends from $10^{\circ} \mathrm{W}$ to $34^{\circ} \mathrm{E}$ and from $25.4^{\circ} \mathrm{S}$ to $50^{\circ} \mathrm{S}$. Its grid, forcing, initial and boundary conditions were built by using the ROMSTOOLS package [Penven, 2003]. Its grid is $441 \times 317$ points with a resolution of $\frac{1}{10}^{\circ}$ corresponding to a mean grid spacing of $9 \mathrm{~km}$, which correctly samples the first baroclinic Rossby radius of deformation throughout the whole area. The grid is isotropic with no introduction of asymmetry in the horizontal dissipation of turbulence. It, therefore, allows a fair representation of mesoscale dynamics. The bottom topography is derived from a $2^{\prime}$ resolution database. The bathymetry is filtered to keep a slope parameter smaller than 0.3. The model has 32 vertical levels, and the vertical s-coordinate is stretched for boundary layer resolution. All the model external forcing functions are derived from different climatologies. Indeed, at the surface, the model heat and fresh water fluxes are extracted from COADS climatology. For the wind stress, a monthly mean climatology is computed from QuikSCAT satellite scatterometer data. At the four lateral boundaries facing 
the open ocean, an active, implicit, upstream-biased, radiation condition connects the model solution to the surroundings [Marchesiello et al., 2001]. Under inflow conditions, the solution at the boundary is nudged toward temperature-, salinity- and geostrophic velocity-fields calculated from Levitus 1998 climatology and also used as initial conditions; the geostrophic velocity is referenced to the 2000 dbar level. We performed an 11-year simulation, and model outputs were averaged and stored every 2 days of simulation.

\subsection{Lagrangian Particles}

The ARIANE toolkit is an off-line Lagrangian diagnostic tool dedicated to the analysis of simulations run with numerical ocean models [Blanke and Raynaud, 1997, http://www. univ-brest.fr/Ipo/ariane]. The incoming transport across a given initial section can be described by hundreds of thousands of particles, and each of them is associated with an infinitesimal fraction of the mass flux. These infinitesimal volumes are conserved along model streamlines, and directional transports can be estimated by adding the transports of the particles that reach equivalent final sections. As described by Blanke et al. [1999], the passage of each particle is recorded, and the volume represented by this particle is summed up at each velocity point of the model grid. The resulting three-dimensional non-divergent transport field is integrated along the vertical direction and pictured as a streamfunction. Though the isolines do not necessarily match individual trajectories, they show the general features of the movement (e.g., Fig. 1), and their spacing characterizes the spreading along the movement.

In order to calculate a robust transport estimate, we performed two Lagrangian experiments. At first, we released particles in the Agulhas Current, at $32^{\circ} \mathrm{S}$ (red solid line in 
Fig. 1) over the simulation-year 4, and we integrated their trajectories over the next 7 years. Then, we released particles on the Atlantic section (red dash-dotted line in Fig. 1) over the simulation-year 11, and we integrated their trajectories over the previous 7 years. For both experiments, we calculated the transport transmitted from the Indian to the Atlantic with appropriate sensitivity tests on the total number of particles and on the length of the Lagrangian integrations. About 43000 (out of about 176 000) make the connection between the Agulhas Current and the Atlantic Ocean. All of them cross the so-called Cape Cauldron region [Boebel et al., 2003a, Fig. 1]. In this region, we sampled particle positions every 6 hours, which is required by the Lagrangian spin-parameter analysis.

\subsection{Statistical Analysis and Spin Parameter}

We used the spin parameter to analyze the trajectories in order to separate the regime of loopers from that of the nonloopers. The mean spin is calculated from the Lagrangian eddy velocities $u^{\prime}, v^{\prime}$ along the trajectories [Sawford, 1991], as

$\Omega=\frac{<u^{\prime} \mathrm{d} v^{\prime}-v^{\prime} \mathrm{d} u^{\prime}>}{2 \Delta t \mathrm{EKE}}$

where EKE is the eddy kinetic energy equal to $\left(<u^{\prime 2}>+<v^{\prime 2}>\right) / 2$. The method consists in characterizing each trajectory (or suitable "chunks" of them) with an average spin value; then, the loopers are distinguished from the nonloopers by considering a cutoff spin value, $\Omega_{0}$, which depends on the global properties of the trajectory ensemble (spin probability density function, shape of velocity auto and crosscovariance functions) [Veneziani et al., 2005b]. For our application, the eddy velocity field is computed by subtracting a bicubic spline-interpolated mean flow from the total Lagrangian velocities. The trajectories are, then, subdivided in chunks of $T_{\text {chunk }}=30$ days chosen as a time scale 
longer than the typical loopers rotation scale and shorter than the expected residence time in a given structure. The trajectories are divided according to their range of depth and classified as being shallower or deeper than $200 \mathrm{~m}$. Given the large size of the whole Lagrangian data set, the statistical analysis is carried out for two random $10 \%$ subsets, and the results are checked to agree within the error estimates.

After performing an extensive sensitivity analysis (by varying $T_{\text {chunk }}$ between 10 and 60 days and the cut-off spin, $\Omega_{0}$, between 0.1 and 0.3 days $^{-1}$ ), the optimal $\Omega_{0}$ values were chosen as $\Omega_{0 s}=0.30$ days $^{-1}$ for the shallower trajectories and $\Omega_{0 d}=0.15$ days $^{-1}$ for the deeper ones. Fig. 2 illustrates typical results for the deeper trajectories. Cyclonic trajectories are separated from anticyclonic ones on the basis of the $\Omega$ sign [cyclonic (anticyclonic) chunks have $\Omega<(>)-(+) \Omega_{0}$ ]. The statistical properties of the looper/nonlooper regimes appear markedly different with the loopers characterized by a significant lobe in the velocity autocovariance functions and a peak in the crosscovariances, both indicative of rotational motion (Fig. 3). We found very similar behaviors for meridional auto- and cross-covariances and for shallower trajectories.

The transport associated with each regime was obtained by multiplying the specific transport of each particle by the relative time spent in the assigned regime, and summing up all the particle contributions. It is worth noting that the spin-based method is conceptually similar to the vortex-based one used by Boebel et al. [2003a] despite the much lower cut-off values $\left(\approx 0.045\right.$ days $\left.^{-1}\right)$ chosen by these authors whose aim was more to consider all of the features with a significant vorticity sign than to identify trapping eddy regimes. 


\section{Results and Discussion}

The 11-year simulation showed the development of a high-level mesocale activity characterized by the generation of Agulhas rings and the shedding of cyclonic eddies from the southern tip of the Agulhas Bank and from the Benguela slope. Off the west coast, the meanders, plumes and filaments developed in a realistic way by the upwelling front indicate of strong variability. We analyzed the average behavior of the model solution and its variability; it evidenced a fair agreement between simulated and observed circulation patterns, both at the surface and at deeper levels (not shown). In our model, the Agulhas current section at $32^{\circ} \mathrm{S}$ exhibits an annual mean transport of $51.0 \mathrm{~Sv}$, and this flux is concentrated in the upper $1200 \mathrm{~m}$. This value is comparable with the $65 \mathrm{~Sv}$ estimated from hydrographic data and reported by de Ruijter et al. [1999] (and references therein). More recently, Boebel et al. [2003a] evaluated a RAFOS float data-based transport of $32 \pm 15 \mathrm{~Sv}$. By using numerical models and an Eulerian approach, Reason et al. [2003] calculated an annual mean value of $61.3 \mathrm{~Sv}$ at $35^{\circ} \mathrm{S}$ in the Indian Ocean, whereas Matano and Beier [2003] found $43 \mathrm{~Sv}$ at $32^{\circ} \mathrm{S}$.

The Lagrangian transport streamlines that reach the Indian and Southern sections (Fig. 1) represent the flow recirculating in the Agulhas Return Current, leaving the Agulhas Plateau towards the north and south, respectively. For these sections we calculated a transport of 23.3 and $12.5 \mathrm{~Sv}$, respectively. The quasi-stationary meandering pattern of the Agulhas Retroflection Current [Boebel et al., 2003b] is very well evidenced by the integrated diagnostic of particle displacement. The overall transport of $35.8 \mathrm{~Sv}$ through these sections is comparable with the $39 \mathrm{~Sv}$ found at $40^{\circ} \mathrm{S}$ by Matano and Beier [2003]. 
The particles released in the Agulhas current that reach the Atlantic section account for 14.5 Sv. This value was confirmed by the second Lagrangian experiment: indeed, a backward integration showed an Indian-Atlantic leakage of $14.2 \mathrm{~Sv}$ (not shown). One should note that the remaining $0.7 \mathrm{~Sv}$ (left from the $51 \mathrm{~Sv}$ entering the Agulhas section after subtracting the $50.3 \mathrm{~Sv}$ exiting through the Indian, Southern, and Atlantic sections) represent particles that either exit at the Agulhas section itself $(0.4 \mathrm{~Sv})$ under the Agulhas Current core at a mean depth of about $2100 \mathrm{~m}$, or remain trapped in the domain at the end of the time integration (0.3 Sv). de Ruijter et al. [1999] reported a compilation of geostrophic estimates of the direct flux of Indian Ocean Water into the South Atlantic, varying from 4 [Garzoli et al., 1996] to $15 \mathrm{~Sv}$ [Gordon et al., 1992]. In close resemblance to our sections, Boebel et al. [2003a] estimated the outflowing transport across their western and northern sections (our Atlantic section of Fig. 1) as being $7 \pm 9 \mathrm{~Sv}$ and $3 \pm 8 \mathrm{~Sv}$, respectively. For numerical model estimates, Reason et al. [2003] calculated $15.5 \mathrm{~Sv}$ at $35^{\circ} \mathrm{S}$, and Donners and Drijfhout [2004] estimated a $18.2 \mathrm{~Sv}$ leak from the Indian Ocean to the South Atlantic.

Spin analysis on the first $10 \%$ random subset of trajectories suggests a percentage of $17.4 \pm 2.0 \%$ for cyclonic looper chunks, $12.8 \pm 1.7 \%$ for anticyclonic ones and $69.8 \pm 1.7 \%$ for nonlooper chunks. The margin of error corresponds to the radius of the asymptotic (and approximated) 99.9 percent confidence interval for each percentage. Multiplying these percentages by the $14.5 \mathrm{~Sv}$ transport let us estimate a transport of $2.5 \pm 0.9 \mathrm{~Sv}$ for cyclones, $1.9 \pm 0.8 \mathrm{~Sv}$ for anticyclones and $10.1 \pm 0.9 \mathrm{~Sv}$ for nonloopers. The associated error includes the effects of: i) the random sub-sampling used in the spin analysis, ii) 
DOGLIOLI ET AL.: LAGRANGIAN ANALYSIS OF INDIAN-ATLANTIC EXCHANGE $\quad$ X - 11

the mismatch between the forward and backward integrations and iii) the existence of slow particles with uncertain fate. These results suggest that most of the interocean exchange occurs in the nonloopers regime, whereas the looper regime represents a sizable $30.2 \%$ of the Indo-Atlantic exchange with a remarkable contribution due to cyclones. The ratio between cyclones and anticyclones transport is 1.3 , which is quite similar to results reported by Boebel et al. [2003a] and based on real drifter trajectories, where cyclones outnumber anticyclones by a factor of 1.5 .

\section{Conclusions}

The oceanic region around Southern Africa is a critical water mass crossroad within the so-called warm-water route of the global overturning circulation [Gordon, 2003], and the Indo-Atlantic connection appears to be crucial in global ocean models [Speich et al., 2001, 2002]. Nevertheless, recent studies based on observations have challenged this hypothesis because of the highly-nonlinear regime found in the Cape Basin. Turbulence is so intense in the area that it could prevent the continuous advection of Indian or South Atlantic waters [de Ruijter et al., 1999; Boebel et al., 2003a]. In order to better evaluate the net mass exchanges across this complex region, we used objective and quantitative diagnostic tools to estimate the proportion of Agulhas leakage. We first developed a high resolution ocean model, which reproduced fairly well the vigorous stirring and mixing processes characterizing the area under study. Then, the Lagrangian particle-following technique provided an estimate of Agulhas leakage of about $14 \mathrm{~Sv}$, which is consistent with observations and previous results from lower resolution models. Finally, the spin analysis of particle trajectories associated with an infinitesimal transport allowed us to estimate 
the transport contribution of mesoscale trapping eddies. We found that the looper regime accounts for about $30 \%$ of the estimed interocean exchange, with a remarkable contribution due to cyclones. These results agree with conclusion by Boebel et al. [2003a] who pointed out the role played by cyclones and showed that Indian water is injected into the Cape Cauldron not only at the surface, but also at intermediate depths. Moreover, the reduced contribution of anticyclones could result from exchange processes with the ambient water, at intermediate depths, liable to occur in the Agulhas rings within this turbulent region. Lagrangian computations coupled with spin analyses revealed promising results, and it would be worth conducting a more complete study to accurately evaluate the net exchange of properties across the Cape Basin and the complex role of mesoscale processes liable to affect water mass origins and fates. In particular, the exact differentiation of both looper regimes in terms of specific pathways for mass transfer and physical characteristics of identified coherent eddies are currently under investigation.

Acknowledgments. The authors warmly acknowledge Delphine Blanke for expert assistance in statistical interpretation and Marie-Paule Friocourt for precious help in manuscript corrections. A. M. Doglioli is supported by SHOM, under contract number CA 2003/03/CMO (Contact: Alain Serpette). This study is a contribution to InterUp, a project funded by the "Programme national Atmosphère et Océan à Multi-échelles" (PATOM), and to the program "Circulation Oceanique" by IFREMER. M. Veneziani and A. Griffa are supported by Consiglio Nazionale delle Ricerche (CNR), Italy. 


\section{References}

Blanke, B., and S. Raynaud (1997), Kinematics of the Pacific Equatorial Undercurrent: An Eulerian and Lagrangian approach from GCM results, J. Phys. Oceanogr., 27, 10381053.

Blanke, B., M. Arhan, S. Speich, and G. Madec (1999), Warm water paths in the equatorial Atlantic as diagnosed with a general circulation model, J. Phys. Oceanogr., 29, 27532768.

Boebel, O., J. Lutjeharms, C. Schmid, W. Zenk, T. Rossby, and C. Barron (2003a), The cape cauldron: a regime of turbulent inter-ocean exchange, Deep-Sea Res. II, 50, 57-86.

Boebel, O., T. Rossby, J. Lutjeharms, W. Zenk, and C. Barron (2003b), Path and variability of the Agulhas Return Current, Deep-Sea Res. II, 50(1), 35-56.

de Ruijter, W. P. M., A. Biastoch, S. S. Drijfhout, J. R. E. Lutjeharms, R. P. Matano, T. Pichevin, P. J. van Leeuwen, and W. Wijer (1999), Indian-Atlantic interocean exchange: Dynamics, estimation and impact, J. Geophys. Res., 104(C9), 20 885-20910.

Donners, J., and S. S. Drijfhout (2004), The Lagrangian view of South Atlantic interocean exchange in a global ocean model compared with inverse model results, J. Phys. Oceanogr., 34, 1019-1035.

Garzoli, S. L., A. L. Gordon, V. M. Kamenkovich, D. Pillsbury, and C. Duncombe Rae (1996), Variability and sources of the southeastern Atlantic circulation, J. Mar. Res., $54(6), 1039-1071$.

Gordon, A. L. (1986), Interocean exchange of thermocline water, J. Geophys. Res., 91, $5037-5046$. 
Gordon, A. L. (2003), The brawniest retroflection, Nature, 421(6926), 904-905.

Gordon, A. L., R. F. Weiss, W. M. Smethie, and M. J. Warner (1992), Thermocline and Intermediate Water Communication between the South-Atlantic and Indian Oceans, J. Geophys. Res., 97, 7223-7240.

Lutjeharms, J. R. E., O. Boebel, and H. T. Rossby (2003), Agulhas cyclones, DeepSea Res. II, 50, 13-34.

Marchesiello, P., M. J. C., and A. Shchepetkin (2001), Open boundary condition for long-term integration of regional oceanic models, Ocean Model., 3, 1-21.

Matano, R. P., and E. J. Beier (2003), A kinematic analysis of the Indian/Atlantic interocean exchange, Deep-Sea Res. II, 50, 229-249.

Penven, P. (2003), ROMSTOOLS user guide, Tech. rep., Inst. de Rech. pour le Dév., Paris, France, http://www.brest.ird.fr/roms_tools.

Reason, C. J. C., J. R. E. Lutjeharms, J. Hermes, A. Biastoch, and R. Roman (2003), Inter-ocean fluxes south of Africa in an eddy-permitting model, Deep-Sea Res. II, 50, 281-298.

Richardson, P. L. (1993), A census of eddies observed in North Atlantic SOFAR float data, Prog. Oceanogr., 31(1), 1-50.

Sawford, B. L. (1991), Reynolds number effects in Lagrangian stochastic models of turbulent dispersion, Phys. Fluids, A3, 1577-1586.

Schmid, C., O. Boebel, W. Zenk, J. R. E. Lutjeharms, S. L. Garzoli, P. L. Richardson, and C. Barron (2003), Early evolution of an Agulhas Ring, Deep-Sea Res. II, 50(1), 141-166. 
Shchepetkin, A. F., and J. C. McWilliams (2005), The regional oceanic modeling system (ROMS): a split-explicit, free-surface, topography-following-coordinate oceanic model, Ocean Model., 9, 347-304.

Speich, S., B. Blanke, and G. Madec (2001), Warm and cold water paths of a O.G.C.M. thermohaline conveyor belt, Geophys. Res. Lett., 28(2), 311-314, doi: 10.1029/2000GL011748.

Speich, S., B. Blanke, P. de Vries, S. Drijfhout, K. Döös, A. Ganachaud, and R. Marsh (2002), Tasman leakage: A new route in the global ocean conveyor belt, Geophys. Res. Lett., 29(10), 1416, doi:10.1029/2001GL014586.

Veneziani, M., A. Griffa, Z. D. Garraffo, and E. P. Chassignet (2004), Lagrangian spin parameter and coherent structures from trajectories released in a high-resolution ocean model, J. Phys. Oceanogr., 34(8), 1884-1906.

Veneziani, M., A. Griffa, Z. D. Garraffo, and E. P. Chassignet (2005a), Lagrangian spin parameter and coherent structures from trajectories released in a high-resolution ocean model, J. Mar. Res., 63, 753-788.

Veneziani, M., A. Griffa, A. M. Reynolds, Z. D. Garraffo, and E. P. Chassignet (2005b), Parameterizations of eddy statistics and particle dispersion in the presence of coherent vortices, J. Mar. Res., 63, 1057-1083. 
Figure 1. Results of first Lagrangian experiment. Shaded colors show bathymetry [m]. Contour lines represent integrated diagnostic of particle displacement (c.i. 2 Sv). The four sections of interception are also shown in red: "Agulhas current" (solid line), "Indian ocean" (dashed line), "Southern Ocean" (dotted line), and "Atlantic Ocean" (dash-dotted line). The yellow line encloses the "Cape Cauldron" region [Boebel et al., 2003a].

Figure 2. Trajectories of two particles (solid and dotted lines). The color code is based on the chunk regime: nonlooper (black), cyclonic (red) and anticyclonic (blue). A velocity vector is reported at the beginning of each chunk.

Figure 3. Zonal (A) auto- and (B) cross-covariance functions of the deeper trajectories. The three different regimes are shown: nonloopers (solid line), cyclones (dash-dotted line) and anticyclones (dashed line). 


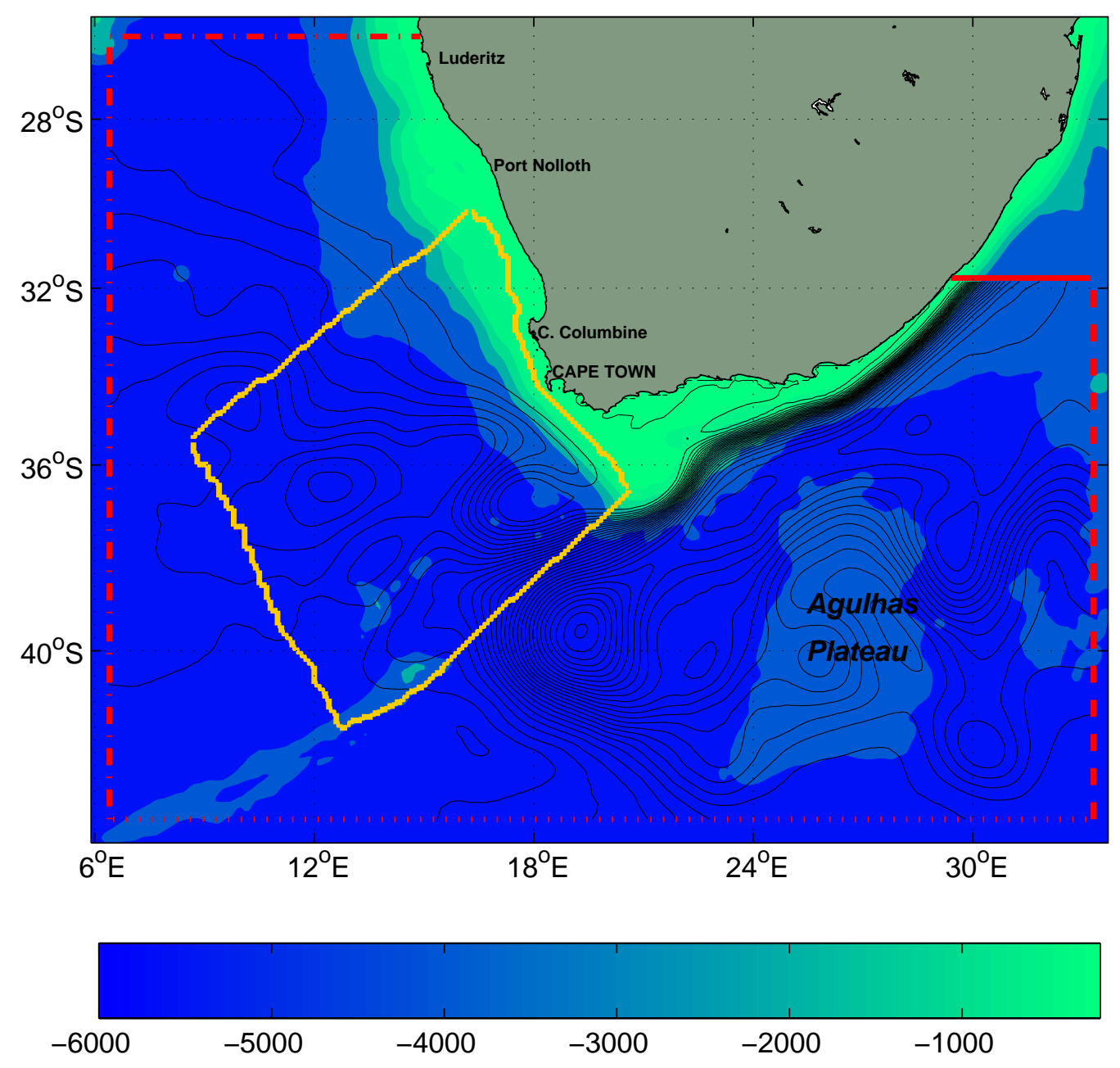




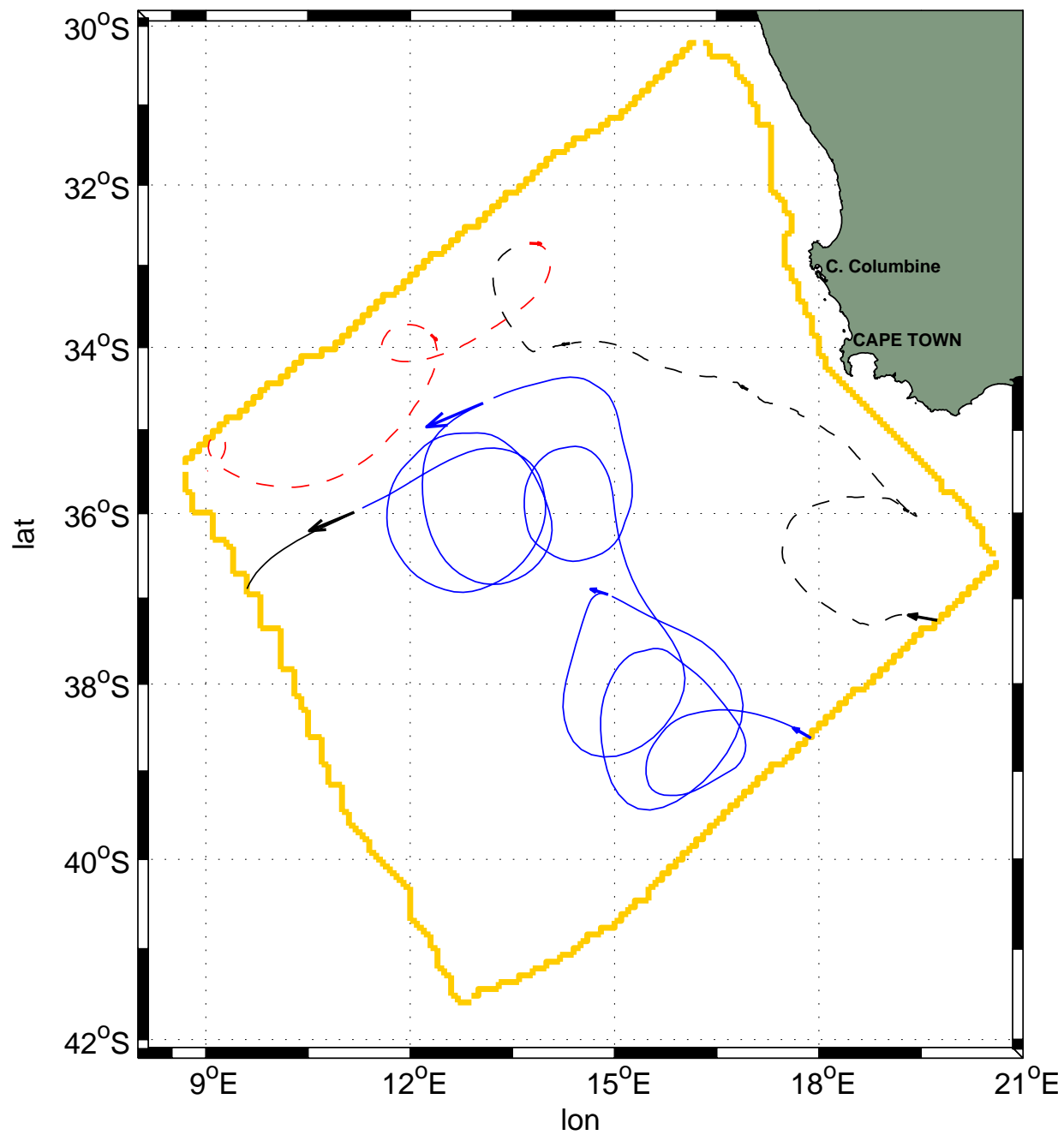


A

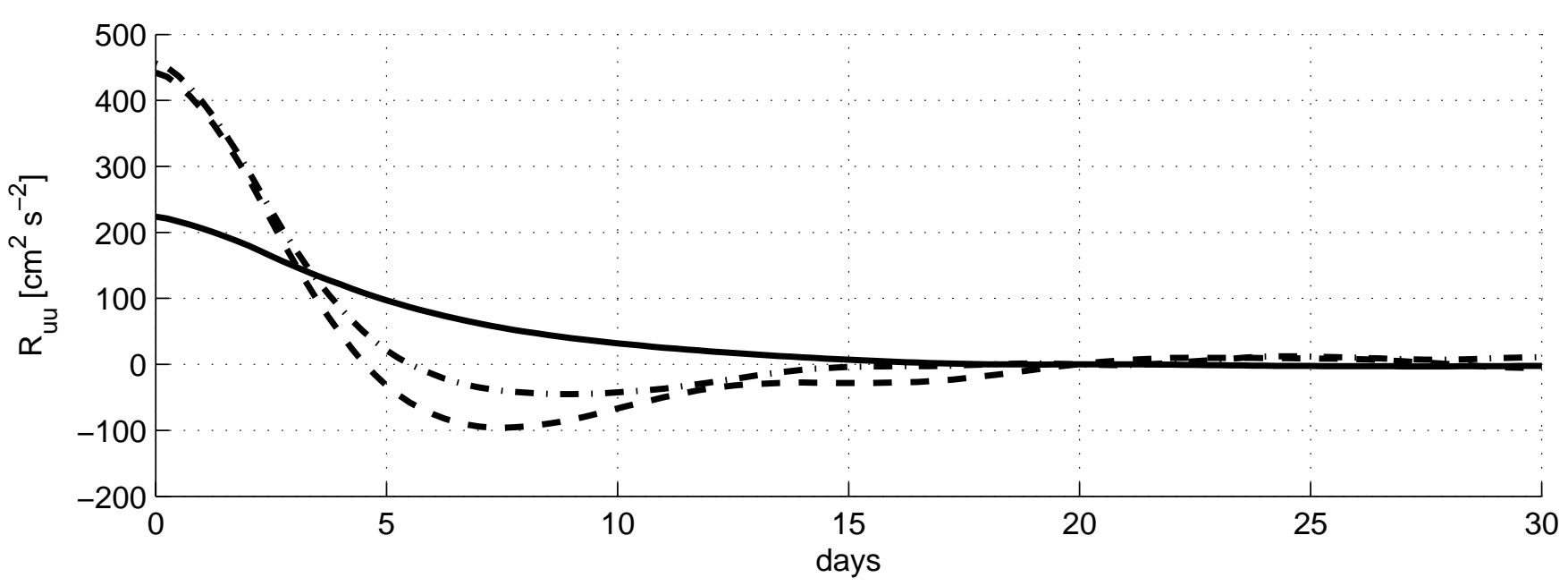

B

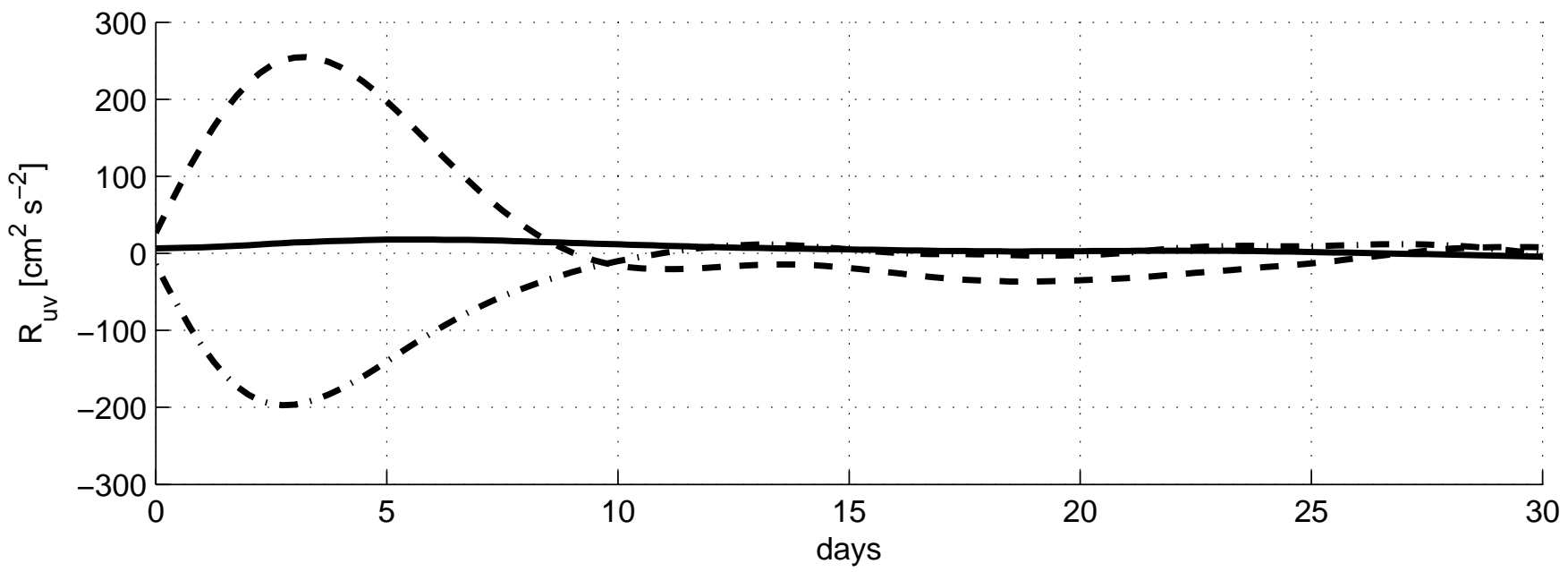

